\title{
Improving Perception and Confidence Toward Bystander Cardiopulmonary Resuscitation and Public Access Automated External Defibrillator Program: How Does Training Program Help?
}

\section{Siew Yee Liaw}

Universiti Malaya

Keng Sheng Chew ( $\nabla$ cksheng74@yahoo.com )

Universiti Malaysia Sarawak https://orcid.org/0000-0002-6326-8210

Ahmad Zulkarnain Ahmad Zahedi

Universiti Malaya

Shirly Siew Ling Wong

Universiti Malaysia Sarawak

Nariman Singmamae

Universiti Malaysia Sarawak

Dev Nath Kaushal

Universiti Malaysia Sarawak

Hiang Chuan Chan

Hospital Umum Sarawak

Research article

Keywords:

Posted Date: April 24th, 2019

DOI: https://doi.org/10.21203/rs.2.9310/v1

License: (c) (1) This work is licensed under a Creative Commons Attribution 4.0 International License.

Read Full License

Version of Record: A version of this preprint was published at International Journal of Emergency Medicine on March 17th, 2020. See the published version at https://doi.org/10.1186/s12245-020-002713. 


\section{Abstract}

Background: In conjunction with an automated external defibrillator (AED) placement program at various locations within a public university in Malaysia, a series of structured training programs were conducted. The objectives of this study is to (1) evaluate the effectiveness of a structured training program in improving the perception of the importance of AED and CPR (2) evaluate the confidence of the employees in using an AED and performing bystander CPR (3) identify the fears and concerns of these employees in using AED and performing CPR (4) determine the perception of these employees towards the strategy of the AEDs placed at various locations within the university. Methods: In this single center observational study, a validated questionnaire aimed to assess the university employees' attitude and confidence in handling AED and performing CPR before (pre-test) and immediately after (post-test) the training program was conducted. Results: A total of 184 participants participated om this study. Using Wilcoxon signedrank test, the training programs appeared to have improved the perception that "using AED is important for unresponsive victims" ( $z=4.32, p<0.001)$ and that "AED practice drills should be performed on a regular basis" $(z=-2.41, p=0.02)$ as well as increased the confidence to perform CPR $(z=-8.56$, $p<0.001)$, use $\operatorname{AED}(z=-8.93, p<0.001)$, identify victims with no signs of life $(z=-7.88, p<0.001)$ and the willingness to perform CPR and AED without hesitancy $(z=-8.91, p<0.001)$. Fears and concerns on performing CPR and using AED also appeared to have been significantly reduced and the perception on placement strategies of these AEDs were generally positive. Conclusion: Using the theory of planned behavior as the explanatory framework, training programs appears to be helpful in improving the perception and the confidence of the participants towards performing CPR and using AED through the promotion of positive attitude, positive societal expectation and a positive sense of empowerment. But whether this positive effect will translate into actual CPR performance and AED application in a real cardiac arrest is yet to be seen.

\section{Background}

As ventricular fibrillation (VF) remains the commonest initial rhythm in sudden out-of-hospital cardiac arrest (OHCA) [1,2], cardiopulmonary resuscitation (CPR) and defibrillation are two pivotal life-saving interventions that increase the chance of survival to hospital discharge [3]. To be effective, these two interventions have to be delivered within minutes from the onset of cardiac arrest [1,4] as it has been shown that with every passing minute without the initiation of cardiopulmonary resuscitation and defibrillation, the chance of survival declines by about $7-10 \%$ [2].

Hence, in order to minimize the time delay from collapse to CPR and defibrillation, these two interventions should be promptly initiated by bystanders [1,5]. For years, the American Heart Association (AHA) recommends for AEDs to be placed in areas with high risk of cardiac arrest [2,6-9]. These AEDs should be easily locatable, placed within the vicinity of the victim, and can be accessible by the bystanders at all time $[1,5,10-12]$. 
Unfortunately, despite the widespread dissemination of AEDs, the effective use of these AEDs in certain communities can still be limited [7-9, 13-17]. In other words, the preparedness of bystander to use AEDs is as important as the placement of the AEDs itself. With proper training and education, bystanders can use these AEDs safely and effectively $[18,19]$.

Kronick et al (2015) outlined four essential components for a successful implementation of a public access AED program: (1) developing a practice plan to respond to an cardiac arrest; (2) training of identified personnel such as the security guards, police and administrative employees as lay rescuers in the skills of CPR and the use of the AED; (3) establishing an integrated link with the local EMS system; and (4) ensuring a program of ongoing quality improvement [20].

In Malaysia, the implementation of public access AED is still a relatively new endeavor. Realizing the importance of public access AED, Universiti Malaysia Sarawak (UNIMAS), a public university in the state of Sarawak, Malaysia, recently implemented the public access AED program and placed 25 units of AED at various strategic locations around the campus [21]. To ensure that non-healthcare employees of UNIMAS are adequately equipped to respond to a sudden OHCA victim, a series of structured training programs were conducted for employees from different faculties and departments in UNIMAS.

Each training program consists of a 60-minute classroom lecture highlighting on the importance of bystander CPR and prompt delivery of shock using AED. The contents of this lecture are based on compiled AHA teaching materials, delivered through slides \& video presentations. This was followed by a hands-on session consisting of skill training on CPR and AED application on manikins.

We embarked on this study with the objectives of (1) evaluating the effectiveness of structured training program in improving the perception of the importance of AED and CPR and (2) improving the confidence of the employees in using an AED and performing CPR (3) identifying the fears and concerns of these employees in using AED and performing CPR (4) determining the perception of these employees towards the placement strategies of the AEDs placed at various locations within the university.

\section{Methods}

This was a single center observational study conducted from February 2018 to November 2018 in conjunction with the CPR and AED skills training program conducted for employees of UNIMAS. Prior to the commencement of the training, the questionnaire forms were distributed to the participants. The participants filled in the questionnaire forms before (pre-test) and after (post-test) the training program. Ethical approval was obtained from the Medical Research and Ethics Committee, Ministry Of Health Malaysia and the study was registered under the Malaysian National Medical Research Register (NMRR, website URL: www.nmrr.gov.my) with the research number of NMRR-16-696-39041.

\section{Participants}


Employees from Universiti Malaysia Sarawak (UNIMAS) who participated in the training program on how to use the AED and perform CPR were invited to participate in this study. Healthcare employees like doctors and paramedic staff were excluded from the study. Informed consent was obtained from all participants prior to their participation in this study.

The sample size for this study was estimated to be 158 based on a previous study on the rate of bystander CPR (of approximately $9 \%$ ) in a community in Malaysia [22]. Single proportion formula with a $95 \%$ confidence interval, margin error of 0.05 and a dropout rate of $20 \%$ was applied. Convenient sampling method was adopted as all participants in this study were also participants of the CPR and AED skills training program.

\section{Materials}

The validated questionnaire used in this study consists of 2 parts. The first part of the questionnaire is to gauge the perceptions of the participants on the implementation strategies of the AEDs placed in UNIMAS campus. The second part of the questionnaire is to assess participants' attitude and confidence in handling AED and performing CPR before (pre-test) and after (post-test) the training program as well as their fears and concerns in using AED and performing CPR.

\section{Procedure}

The self-administered questionnaire survey forms were distributed by one of the researchers (SYL) in conjunction with the CPR and AED skills training programs. Prior to commencing this training program, the participants were asked to fill in the section assessing the pre-test section on the perception, confidence and fears and concerns on performing CPR and using AED. The post-test section was filled immediately after the completion of the training program. Informed consent was obtained from all participants. Participants were informed that his or her data would be used anonymously for subsequent analysis, presentation and publication.

\section{Results}

A total of 184 administrative employees from UNIMAS participated in this study. The mean age group of the participants was 37.6 years (SD +/- 6.85); and 100 out of 184 of them (54.3\%) were male participants. The level of education ranged from secondary school level to postgraduate level, with a majority of them (68 or $37 \%$ ) of them being diploma holders. With regards to their working experience in UNIMAS, the mean working experience was 11.5 years (SD +/- 5.43).

Non-parametric tests were used to analyze the associations and correlations of the various variables, as the data is not normally distributed. Using Wilcoxon signed-rank test to determine the effectiveness of a training program to improve the perception of using AED and performing CPR ("pre-test" vs "post-test"), statistically significant improvement was noted in the perception that "using an AED is important for any unresponsive victims" and that "AED practice drills should be performed on a regular basis" with $z=-4.32$, 
$p<0.001$ and $z=-2.41, p=0.02$ respectively. Similarly, with regards to confidence in using the AED and performing $C P R$, the results show that the training program improved the confidence to perform $\mathrm{CPR}(\mathrm{z}=$ -8.56, $p<0.001)$, confidence to use AED $(z=-8.93, p<0.001)$, confidence to identify signs of victims with no signs of life $(z=-7.88, p<0.001)$ and willingness to perform CPR and AED without hesitancy $(z=-8.91$, $\mathrm{p}<0.001)$. The details of the all pre- vs post-training analysis using Wilcoxon signed-rank test are tabulated in Table 1. Similarly, using Wilcoxon signed-rank test, the training program also seem to have significantly reduced the degree of fear and concerns in performing CPR and using AED (refer to Table 2). With regards to the placement strategies of these AED, more than $50 \%$ of the participants agreed that the AEDs were visibly placed (125 out of or $67.9 \%$ ) in secure location (122 participants or $66.3 \%$ ) with clear signage (113 participants or $61.4 \%$ ), good accessibility (112 participants or $60.7 \%$ ) and easy-to-follow instructional poster (99 participants or 53.8\%) (see Table 3 ).

Using Spearman's rank-order correlation, the correlation between the confidence to perform CPR with the confidence to use AED was strong, $r s(182)=0.87, p<0.001$ as well as the correlation between the confidence to perform CPR with the confidence to recognize victim with no signs of life, $r s(182)=0.65, p$ $<0.001$. Similarly, the correlation between the confidence to use AED with the willingness to initiate the use of AED without hesitancy was strong with $r s(182)=0.80, p<0.001$.

\section{Discussion}

To aid answering the question of how a structured training program can help to improve the willingness of the participants to perform CPR and to use public access AEDs, two theoretical frameworks were adopted, i.e., Kirkpatrick training evaluation model [23] and the theory of planned behavior (TPB) [24]. Kirkpatrick training evaluation model is a tool used to evaluate the levels of participants' responses towards a training program [23]. In this model, Level 1 is known as the "reaction" level. This level is merely an experiential level (i.e., whether the participants have had good experience and engagement in the training activities). Real learning might or might not have taken place. Level 2 is known as the "learning level". At this level, participants should have, to large degree, acquired the intended knowledge and skills outlined in the training objectives as well as have instilled some degree of positive attitude, confidence and willingness of the participants to act on the desired learning goals. Level 3 ("behavior level") measures the degree to which participants can actually apply what they had learned during the training (i.e., actually performing CPR and using public access AED in a real OHCA). Level 4 is known as the "results level". This level essentially measures the positive impact of the training for the community as a result from the acquired knowledge and skills (i.e., the actual increased in OHCA survival rate). In this regard, we believed that at this current moment, we have achieved at least level 2 of Kirkpatrick training evaluation model as participants had demonstrated by the improved scores in knowledge, skills as well as attitude after the training.

The theory of planned behavior (TPB) is a three dimensional theoretical framework developed by Ajzen (1991) to understand and predict human behavior [24]. According to Ajzen (1991), the immediate precursor that determines whether person would decide to act on a particular volitional behavior (i.e., the 
act of performing CPR and applying AED when an actual cardiac arrest occurs) is known as the "intention" to perform that behavior [24]. The intention in this study refers to the willingness to perform CPR and AED without hesitancy. In this regard, the training programs did indeed seem to be effective in promoting the positive intention of the willingness to perform CPR and use AED as shown in the pre- vs post-training analysis as shown in Table 1. This intention (willingness to perform CPR and using AED), according to the TPB, in turn, is said to be influenced by three determinants: (1) attitude (2) subjective norm and (3) perceived behavioral control.

A person's attitude toward a particular behavior (i.e., performing CPR and applying AED when an actual cardiac arrest occurs) is developed, either favorably or unfavorably, from the beliefs that he or she holds towards that behavior as well as other attributes associated with the behavior (e.g., the legality concerns and fears of injuring the victims through CPR and AED use, which may negatively impact one's attitude toward this behavior). Behaviors that are believed to have desirable outcomes (i.e., promptly performing CPR and using AED can save lives) tend to be favored whilst behaviors that are believed to have undesirable outcomes are not favored [24]. Hence, it is imperative to instill the notion that prompt initiation of bystander CPR and the prompt use of AED is of paramount importance.

As human is by nature a social creature who highly regards what the society and the signicant people around him or her (e.g. family, friends, colleagues, etc) think of his or her behavior (i.e., the social normative), it is essential that the element of social interaction (such as the group practice of CPR and AED together) is incorporated into the training in order to help dispel the oddity of performing bystander CPR and using AED in public. This is because, according to TPB, if society expects or favors a particular behavior (in this case, the societal norm or expectation to promptly initiate bystander CPR and apply AED), then it is more likely that the individual will have the postive intention to act on this behavior should the need arises [24]. Hence, while we did not explicitly measure the influence of social interaction on the willingness to perform bystander CPR or using AED, we believe that this social interaction and group practice is important to promote the positive intention of willingness to perform CPR and using AED.

The perceived behavioral control, on the other hand, refers to the perceived empowerment or ability to actually perform or engage in the behavior (i.e., performing bystander CPR and using AED) based on the resources and opportunities available to him or her at that particular time [24]. A bystander who felt empowered, or felt that he had the capability to execute the behvior is more likely to perform this task. In this regard, it is imperative to ensure that the employees are trained to operate the specific AEDs located within their reach. This will give them a sense of control or empowerment as they would be the most familiar with the localities that they are working in. Furthermore, according to Ajzen (1991), the perceived behavioral control is also very much dependent on the perceived probability of succeeding at a given task [24]. Hence, it is important to inculcate the confidence of the employees to perform CPR and to use the $A E D$. In this regard, the training program did indeed seem to be effective in increasing the confidence of the employees to use the AED. In fact, positive correlation was demonstrated between the confidence to perform CPR with the confidence to use AED, the correlation between the confidence to perform CPR with the confidence to recognize victim with no signs of life as well as the correlation between the confidence 
to use AED with the willingness to initiate the use of AED without hesitancy (see Figure 1 on how the theory of planned behavior is used as the explanatory framework on how a training program can be helpful).

In summary, to be effective in improving the perception and confidence of the public toward bystander CPR and using AED, the following elements should be incorporated in the training: (1) instilling positive attitude and perception on CPR and AED based on latest scientific evidences that CPR and AED save lives as well as allaying fears and concerns related to CPR and AED. These cognitive inputs can be delivered through lectures and tutorials (2) promoting positive societal expectation that prompt bystander CPR and AED is called for when someone collapses. Such societal norm can be delivered through group CPR participations and social interactions during the skills or practical session (3) promoting a sense of empowerment and confidence that using AED located is within their reach and capability. This can be done by training the right people, e.g. staff working in the building where the AED is located.

A number of limitations deserve mentioning. First, this study involved participants from only one centre and merely involved employees working in an academic center. Hence, it might not be generalizable to include perception from the other different communities and from participants of different levels of educational background. Furthermore, the training program could only possibly achieve the "intention" level in the TPB and up to "level 2 - learning" in the Kirkpatrick training evaluation model. This suggests that at this current moment, the effectiveness of the training program in increasing the actual performance of CPR and AED when an OHCA occurs is yet to be unknown. As stated by Ajzen (1991), for accurate behavioral prediction (on the likelihood to perform CPR and use AED should an actual cardiac arrest occurs), the intentions (i.e. the willingness to perform CPR and use AED) and perceived behavioral control (i.e. confidence to perform CPR and use AED) should remains stable in the interval between the assessment of these intentions and perceived behavioral control until the actual performance of the behavior [24]. Various intervening events (e.g. seeing the gory of a traumatic accident scene, memory lapse and deterioration of CPR and AED skills, etc) during this time interval may negatively affect the strength of the intention and/or perception of behavioral control. This in turn, may negatively affect the likelihood of carrying out this behavior. Hence, regular training and re-training as well as refresher courses is of utmost importance. Further works could include expanding the training program on the use of public access AED and bystander CPR training program to other community settings as well.

\section{Conclusion}

In conclusion, this study suggest that a training program is effective in improving the perception and the confidence of the participants towards performing CPR and using AED although whether this positive effect is likely to translate into actual CPR performance and AED application should a real OHCA incident occurs yet remains to be seen.

\section{Declarations}


Ethics approval and consent to participate: Ethical approval was obtained from the Medical Research and Ethics Committee, Ministry Of Health Malaysia and the study was registered under the Malaysian National Medical Research Register (NMRR, website URL: www.nmrr.gov.my) with the research number of NMRR-16-696-39041. Informed consent was obtained from all participants prior to their participation in this study.

Consent for publication: Participants were informed that his or her data would be used anonymously for subsequent analysis, presentation and publication."

Availability of data and material: The dataset is not available not publicly available due to personal data such as age, gender, occupation, years of experience; however, it may be requested from the corresponding author upon reasonable request.

Competing interests: No competing of interest declared.

Funding: Not applicable.

Authors' contributions: All authors were involved in the initial conception of the study design. SYL, NS and DNK were involved in conducting the study; SYL, KSC and SSLW were involved in analyzing and interpreting the results. SYL and KSC were involved in writing up the draft of the manuscript to be approved by all authors.

Acknowledgements: The authors would like to thank all participants from UNIMAS who had participated in the CPR and AED training program and also this study project. The authors also would like to thank the employees who ere involved in the validation of the questionnaire.

\section{References}

1. Valenzuela TD, Roe DJ, Cretin S, Spaite DW, Larsen MP. Estimating effectiveness of cardiac arrest interventions: a logistic regression survival model. Circulation. 1997;96(10):3308-13.

2. Link MS, Atkins DL, Passman RS, Halperin HR, Samson RA, White RD, et al. Part 6: electrical therapies: automated external defibrillators, defibrillation, cardioversion, and pacing: 2010 American Heart Association Guidelines for Cardiopulmonary Resuscitation and Emergency Cardiovascular Care. Circulation. 2010;122(18 Suppl 3):S706-19.

3. Larsen MP, Eisenberg MS, Cummins RO, Hallstrom AP. Predicting survival from out-of-hospital cardiac arrest: a graphic model. Ann Emerg Med. 1993;22(11):1652-8.

4. Holmberg M, Holmberg S, Herlitz J. Effect of bystander cardiopulmonary resuscitation in out-ofhospital cardiac arrest patients in Sweden. Resuscitation. 2000;47(1):59-70.

5. Public-Access Defibrillation and Survival after Out-of-Hospital Cardiac Arrest. N Engl J Med. 2004;351(7):637-46. 
6. Atwood C, Eisenberg MS, Herlitz J, Rea TD. Incidence of EMS-treated out-of-hospital cardiac arrest in Europe. Resuscitation. 2005;67(1):75-80.

7. Kitamura T, Iwami T, Kawamura T, Nagao K, Tanaka H, Hiraide A. Nationwide public-access defibrillation in Japan. N Engl J Med. 2010;362(11):994-1004.

8. McNally B, Robb R, Mehta M, Vellano K, Valderrama AL, Yoon PW, et al. Out-of-hospital cardiac arrest surveillance - Cardiac Arrest Registry to Enhance Survival (CARES), United States, October 1, 2005December 31, 2010. MMWR Surveill Summ. 2011;60(8):1-19.

9. Ong ME, Shin SD, De Souza NN, Tanaka H, Nishiuchi T, Song KJ, et al. Outcomes for out-of-hospital cardiac arrests across 7 countries in Asia: The Pan Asian Resuscitation Outcomes Study (PAROS). Resuscitation. 2015;96:100-8.

10. Page RL, Joglar JA, Kowal RC, Zagrodzky JD, Nelson LL, Ramaswamy K, et al. Use of automated external defibrillators by a U.S. airline. N Engl J Med. 2000;343(17):1210-6.

11. Enami M, Takei Y, Goto Y, Ohta K, Inaba H. The effects of the new CPR guideline on attitude toward basic life support in Japan. Resuscitation. 2010;81(5):562-7.

12. Berdowski J, Blom MT, Bardai A, Tan HL, Tijssen JG, Koster RW. Impact of onsite or dispatched automated external defibrillator use on survival after out-of-hospital cardiac arrest. Circulation. 2011;124(20):2225-32.

13. Delhomme C, Njeim M, Varlet E, Pechmajou L, Benameur N, Cassan P, et al. Automated external defibrillator use in out-of-hospital cardiac arrest: Current limitations and solutions. Arch Cardiovasc Dis. 2019. Article in press. Available at URL: https://doi.org/10.1016/j.acvd.2018.11.001 Accessed 19 March 2019

14. Culley LL, Rea TD, Murray JA, Welles B, Fahrenbruch CE, Olsufka M, et al. Public access defibrillation in out-of-hospital cardiac arrest: a community-based study. Circulation. 2004;109(15):1859-63.

15. Fleischhackl R, Roessler B, Domanovits H, Singer F, Fleischhackl S, Foitik G, et al. Results from Austria's nationwide public access defibrillation (ANPAD) programme collected over 2 years. Resuscitation. 2008;77(2):195-200.

16. Kitamura T, Iwami T, Kawamura T, Nitta M, Nagao K, Nonogi $H$, et al. Nationwide improvements in survival from out-of-hospital cardiac arrest in Japan. Circulation. 2012;126(24):2834-43.

17. Siddiq AA, Brooks SC, Chan TCY. Modeling the impact of public access defibrillator range on public location cardiac arrest coverage. Resuscitation. 2013;84(7):904-9.

18. Mosesso VN, Jr., Davis EA, Auble TE, Paris PM, Yealy DM. Use of Automated External Defibrillators by Police Officers for Treatment of Out-of-Hospital Cardiac Arrest. Annals of emergency medicine. 1998;32(2):200-7. 
19. White RD, Hankins DG, Bugliosi TF. Seven years' experience with early defibrillation by police and paramedics in an emergency medical services system. Resuscitation. 1998;39(3):145-51.

20. Kronick SL, Kurz MC, Lin S, Edelson DP, Berg RA, Billi JE, et al. Part 4: Systems of Care and Continuous Quality Improvement: 2015 American Heart Association Guidelines Update for Cardiopulmonary Resuscitation and Emergency Cardiovascular Care. Circulation. 2015;132(18 Suppl 2):S397-413.

21. UNIMAS News. Public Access Defibrillation (PAD) Training for UNIMAS Staff. Available at URL: https://tinyurl.com/y32l8hnn Accessed 19 March 2019

22. Chew KS, Mohd Idzwan Z, Nik Hishamuddun NA, Wan Aasim WA, Kamaruddin J. How frequent is bystander cardiopulmonary resuscitation performed in the community of Kota Bharu, Malaysia? Singapore Med J. 2008;49(8):636-9.

23. Smidt A, Balandin S, Sigafoos J, Reed VA. The Kirkpatrick model: A useful tool for evaluating training outcomes. Journal of Intellectual \& Developmental Disability. 2009;34(3):266-74.

24. Ajzen I. The theory of planned behavior. Organizational Behavior and Human Decision Processes. 1991;50(2):179-211.

\section{Tables}

Table 1 Effectiveness of training to improve the perception and confidence in using AED and performing bystander CPR 
Variable

Number of cases where post-training score $>$ pretraining score (mean

rank)
Number of cases where post-training score < pretraining score (mean rank)

\section{Perception of the}

participants1

AED is life saving

$30(25)$

$19(25)$

1.57

0.12

It is important for an AED

to be available in the

$26(21)$

$15(21)$

$1.72 \quad 0.09$

place where I work.

Using an AED is important for any

unresponsive victims.
$42(27.4)$

$11(25.5)$

$4.32<0.001$
Person who handles an

$A E D$ requires formal

training

AED practice drills should be performed on

a regular basis.
$29(23.8)$

$18(24.3)$

1.508

0.31

$33(26.0)$

$17(24.5)$

2.41

0.02

\section{Confidence of the}

participants2

\begin{tabular}{lllll}
$\begin{array}{l}\text { I am confident to perform } \\
\text { CPR. }\end{array}$ & $97(50.4)$ & $3(52.7)$ & 8.56 & $<0.001$ \\
$\begin{array}{l}\text { I am confident to use an } \\
\text { AED }\end{array}$ & $107(56.1)$ & $4(53.0)$ & 8.93 & $<0.001$ \\
$\begin{array}{l}\text { I am confident in } \\
\text { recognizing victim with } \\
\text { no signs of life. }\end{array}$ & $93(52.5)$ & $(41.1)$ & 7.88 & $<0.001$ \\
$\begin{array}{l}\text { I will not hesitate to } \\
\text { perform CPR and use } \\
\begin{array}{l}\text { AED on an unresponsive } \\
\text { victim. }\end{array}\end{array}$ & $106(55.6)$ & $4(53.5)$ & & \\
\hline
\end{tabular}

Note: the higher the score, the positive is the response

Table 2 Fears and concerns of participants in performing CPR and using AED 

Variable
Number of cases where post- training score $>$ pre-training score (mean rank)
Number of cases where post- training score $<$ pre-training score (mean rank)
$\begin{array}{ll}\text { z- } & p- \\ \text { value } & \text { value }\end{array}$

\section{Fears and}

concerns

\begin{tabular}{|c|c|c|c|c|}
\hline $\begin{array}{l}\text { Infection from } \\
\text { performing CPR }\end{array}$ & 24 & 63 & -4.342 & $<0.001$ \\
\hline $\begin{array}{l}\text { Injuring victim } \\
\text { due to } \\
\text { performing CPR }\end{array}$ & 8 & 100 & -8.502 & $<0.001$ \\
\hline $\begin{array}{l}\text { Injuring own } \\
\text { self due to } \\
\text { performing CPR }\end{array}$ & 15 & 63 & -5.380 & $<0.001$ \\
\hline $\begin{array}{l}\text { Injuring victim } \\
\text { due to using } \\
\text { AED }\end{array}$ & 9 & 100 & -8.451 & $<0.001$ \\
\hline $\begin{array}{l}\text { Injuring own } \\
\text { self due to } \\
\text { using AED }\end{array}$ & 11 & 75 & -6.642 & $<0.001$ \\
\hline $\begin{array}{l}\text { Getting sued } \\
\text { due to } \\
\text { performing CPR }\end{array}$ & 8 & 108 & -8.847 & $<0.001$ \\
\hline $\begin{array}{l}\text { Getting sued } \\
\text { due to using } \\
\text { AED }\end{array}$ & 9 & 107 & -8.517 & $<0.001$ \\
\hline
\end{tabular}

Note: the higher the score, the more concerned the participants

Table 3 Participants' opinions on the AED placement strategies.

\section{Domain Criteria}

Number of participants who agreed (\%)

Visibility The AED is placed in a clearly visible location

$125(67.9 \%)$

Signage The signage that shows the location of the AED is clear.

$113(61.4 \%)$

Accessibility

The AED is located in a location that is easily accessible at

all times (including after office hours).

Instruction The steps in the AED instructional poster on how to use the

AED are easy to follow.

Security The AED is located at a secure area.
$112(60.7 \%)$

$99(53.8 \%)$

$122(66.3 \%)$

\section{Figures}




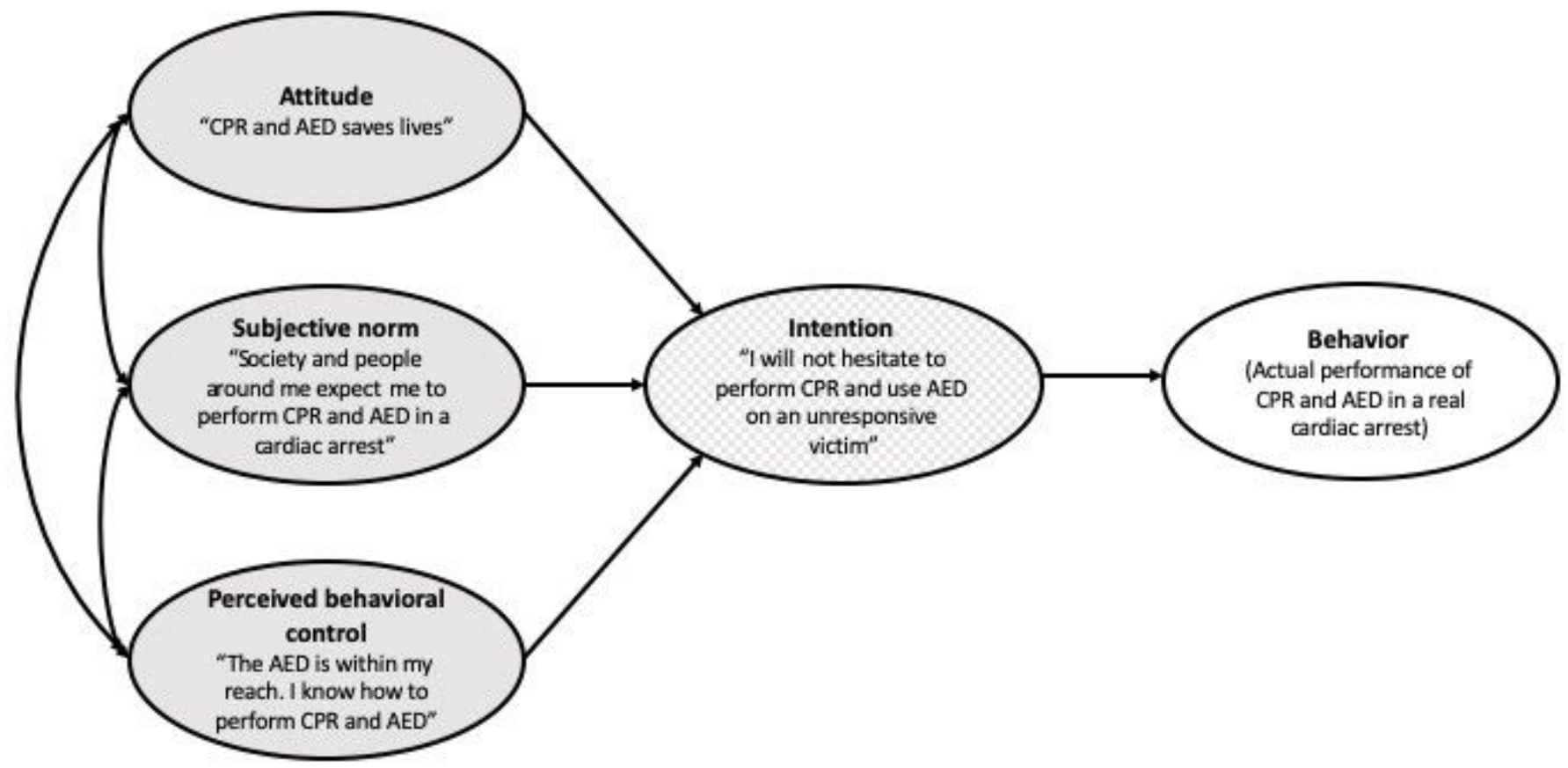

Figure 1

Theory of planned behavior as a framework to explain how a training program can have positive impact on the the intention to perform CPR and use AED 